\title{
Measuring multimorbidity in older adults: comparing different data sources
}

Samantha Gontijo Guerra ${ }^{1,2^{*}}$ (D), Djamal Berbiche ${ }^{1,3}$ and Helen-Maria Vasiliadis ${ }^{1,3}$

\begin{abstract}
Background: Multimorbidity is a global health issue, particularly for older adults in the primary care setting. An adequate portrayal of its epidemiology is essential to properly identify and understand the health care needs of this population. This study aimed to compare the differences in the prevalence of selected chronic conditions and multimorbidity, including its associated characteristics, using health survey/self-reported (SR) information only, administrative (Adm) data only and the combined (either) sources.

Methods: This was a secondary analysis of survey data from the first cycle of the Longitudinal Survey on Senior's Health and Health Services Use linked to health-Adm data. The analytical sample consisted of 1625 communitydwelling older adults ( $\geq 65$ years) recruited in the waiting rooms of primary health clinics in a selected administrative region of the province of Quebec. Seventeen chronic conditions were assessed according to two different data sources. We examined the differences in the observed prevalence of chronic conditions and multimorbidity and the agreement between data sources.
\end{abstract}

Results: The prevalence of each of the 17 chronic conditions ranged from 1.2 to $68.7 \%$ depending on the data source. The agreement between different data sources was highly variable, with kappa coefficients $(\mathrm{k})$ ranging from 0.05 to 0.73. Multimorbidity was very high in this population, with an estimated prevalence of up to $95.9 \%$. In addition, we found that the association between sociodemographic and behavioural factors and the presence of multimorbidity varied according to the different data sources and thresholds.

Conclusions: This is the first study to simultaneously investigate chronic conditions and multimorbidity prevalence among primary care older adults using combined SR and health-Adm data. Our results call attention to (1) the possibility of underestimating cases when using a single data source and (2) the potential benefits of integrating information from different data sources to increase case identification. This is an important aspect of characterizing the health care needs of this fast-growing population.

Keywords: Chronic conditions, Multimorbidity, Prevalence, Epidemiology, Self-report, Health administrative data, Primary health care, Older adults, Data sources, Agreement between sources

\section{Background}

Multimorbidity (MM), the co-occurrence of multiple chronic conditions in an individual [1], is a prominent public health issue that is attracting increasing interest among researchers, practitioners and decision-makers from a variety of disciplines and fields. The primary care setting undertakes a substantial part of the management

\footnotetext{
* Correspondence: samantha.gontijo.guerra@USherbrooke.ca

${ }^{1}$ Centre de recherche Charles-Le Moyne - Saguenay-Lac-Saint-Jean sur les innovations en santé (CR-CSIS), Longueuil, QC, Canada

¿2Université de Sherbrooke, Campus Longueuil, 150 Place Charles-Le Moyne, Longueuil, QC J4K 0A8, Canada

Full list of author information is available at the end of the article
}

of multimorbid patients [2-4], and although MM is not observed exclusively in older adults, this group is particularly affected $[5,6]$. Since MM is undoubtedly a central element of the framework describing the needs of older adults, an adequate description of the epidemiology of concurrent physical and mental health conditions [3, 4, 6$8]$ is essential in informing the responsiveness of health systems $[4,9]$.

The designs of epidemiological MM studies vary greatly, as do their results in terms of prevalence (ranging from 3.5 to 100\%) [10] and associated outcomes [11-14]. This can be partly explained by the lack of

(c) The Author(s). 2019 Open Access This article is distributed under the terms of the Creative Commons Attribution 4.0 International License (http://creativecommons.org/licenses/by/4.0/), which permits unrestricted use, distribution, and 
consensus concerning the conceptual or operational definitions (i.e., the length of the list of conditions, cut points, etc.) $[10,15,16]$, choice of study populations $[17$, $18]$ and data sources [19-21]. It is not always clear, however, which data source is most appropriate to use in epidemiological studies [22].

The objective of comparing different data sources has been well explored in studies considering individual diagnoses (e.g., diabetes, hypertension, cancer) and in those including a relatively small number of diseases [23-26]. These studies have predominantly compared self-reports to chart reviews, medical examinations or practitioner reports [22, 27, 28]. Recently, survey/self-reported (SR) and administrative (Adm) data have been increasingly used in health research [23]. As suggested by Bayliss and colleagues [29], these data sources represent the subjective (patient's perspective) and objective (health systems' perspective) measurements that must be taken into account to make a more comprehensive assessment of morbidity.

We identified only two studies that simultaneously compared the prevalence of chronic conditions and MM using SR and Adm data [30, 31] with one study [30] reporting prevalence estimates measured with the combined (either) data sources. The use of combined data sources in epidemiological studies has been suggested as a promising approach since it allows the perspectives of both the patient and the health system to be taken into account [32-34]. To date, no previous study of this nature (i.e., comparing and combining SR and health-Adm data) has been conducted among older populations of primary health care users, a well-known priority population in terms of MM. Using SR and health-Adm data, individually or combined, the current study aimed to (1) compare the prevalence of selected chronic conditions and MM; (2) examine the agreement between these data sources on selected chronic diseases; (3) examine the factors associated with $\mathrm{MM}$ as a function of data sources and (4) draw out implications for policy and future research.

\section{Methods}

\section{Study design and setting}

This was a secondary analysis of data from the first cycle of the Longitudinal Survey on Senior's Health and Health Services Use (Enquête sur la santé des aînés-Services or ESA-S) linked to health-Adm data. The participants consisted of French-speaking, community-dwelling older adults aged 65 years and over recruited between 2011 and 2013 in the waiting rooms of primary health clinics in a selected administrative region of the province of Quebec. The purpose of the ESA-S survey was to document the episodes of psychological distress and the factors associated with the use of health services for mental health problems in older people. More details on the ESA-S survey methodology can be obtained elsewhere [35]. Eligible candidates were contacted for in-home interviews. To minimize information bias associated with mild to severe cognitive impairment, individuals scoring less than 22 on the Mini-Mental State Examination (MMSE) [36, 37] were excluded at the beginning of the interview. Of the 1811 individuals contacted, 46 scored $\leq 21$ on the MMSE and did not continue the interview. Since the health-Adm and SR data linkage was not achieved for 140 of the 1765 participants who completed the interviews, the analytical sample for this study included 1625 participants.

\section{Data source and collection}

Survey data were collected by trained professionals. During a face-to-face interview, participants responded to a selfreported, computer-administered questionnaire (the ESA-S Q) aimed at collecting sociodemographic, behavioural and clinical information. They were first invited to sign an informed consent form. In addition, each participant was asked to authorize the research team to access their healthAdm data from ministerial databases on claim-based medical services and hospitalization, the Régie de l'Assurance Maladie Québec (RAMQ) and the Maintenance et exploitation des données pour l'étude de la clientèle hospitalière (MED-ÉCHO), respectively. These databases include information allowing, among other things, the identification of diagnoses (according to the International Statistical Classification of Diseases and Related Health Problems, 9th and 10th revisions - ICD-9/ICD-10) and the determination of whether medical care was provided during a hospitalization, an outpatient or an emergency department (ED) visit. Health-Adm and SR databases were linked using the personal health insurance number (Numéro d'assurance maladie - NAM), a unique 10-digit identifier for each beneficiary. In the Canadian province of Quebec, residents are covered by a universal health insurance programme administered by the RAMQ.

\section{Measurements and study variables Chronic conditions}

Self-reported The presence of SR chronic conditions was ascertained based on participants' answers (yes/no) to the following question, "To your knowledge, and according to a physician, do you have [...]". Briefly, participants were invited to inform if they had been diagnosed with one or more chronic conditions out of a list of 15: dermatologic conditions, arthropathy, cancer, headaches, diabetes, liver disease, hyperlipidemia, hypertension, cardiovascular disease/atherosclerosis, eye diseases, respiratory tract disease (i.e., bronchitis, asthma, emphysema, persistent cough), chronic urinary tract problem, thyroid problems, gastrointestinal diseases, and musculoskeletal 
conditions (i.e., chronic neck/back pain). Moreover, the presence of depressive and anxiety symptoms was ascertained using the ESA-S Q Mental-Diagnostic Module based on the Diagnostic and Statistical Manual of Mental Disorders, 5th edition (DSM- 5) and other literature sources [38-40]. The presence of depressive (major, minor and subclinical) and anxiety (specific phobia, social phobia, agoraphobia, panic disorder, and generalized anxiety disorder-GAD) conditions was then defined [38-40]. We defined common mental health disorders as the presence of anxiety and/or depressive conditions. Last, participants were also asked to report their weight and height so that their body mass index (BMI) could be calculated and self-reported obesity (defined as a BMI $\geq$ 30) [41] ascertained.

Physician diagnosis based on administrative records Two health-Adm databases (RAMQ medical services claim-based and MED-ÉCHO hospital stay) were used to identify participants' chronic conditions. The ICD-9/ ICD-10 codes were used to extract information from these databases (over a three-year period prior to the interview) for each of the 17 conditions reported by the participants. The selection of the ICD-9/10 codes was mostly guided by a list proposed by a group of experts from the International Research Community on Multimorbidity (IRCMo). This list was also completed by literature review $[40,42-45]$ in the case of disease categories that were not included in the expert group's list (e.g., eye disease, dermatologic disease and chronic headaches). An additional table shows the list of 17 chronic condition categories and the corresponding ICD-9 and ICD-10 codes (see Additional file 1).

Combined data sources Each of the 17 chronic conditions was also assessed using combined data sources (either SR or Adm).

\section{Multimorbidity (MM) variables}

For each of the three datasets (i.e., SR only, Adm only, combined sources/either SR or Adm), a count of conditions was created by summing up the total number of chronic conditions, ranging from 0 to 17 . Six MM variables were then operationalized according to (1) two different cut-offs frequently used in the literature, i.e., more than 2 (MM2) and more than 3 (MM3) conditions [11, 12, 46] and (2) the type of data source. They were named as follows: MM2_SR, MM2_Adm, MM2_Either, MM3_SR, MM3_Adm, and MM3_Either.

\section{Other study variables}

We also assessed participants' gender (male; female), age groups $(65-69,70-74 ; 75-79 ; 80-84 ; 85-89$; $\geq 90)$, education in years $(\leq 7 ; 8-12 ; \geq 13)$, annual household income in $\$ C A N(<25,000 ; \geq 25,000)$, current marital status (with partner; without partner), perceived mental and physical health (excellent/very good; good; fair/ poor), and smoking habits (never; former; current smoker). Social support (SS) was assessed using three dichotomous (0/1) questions about the availability of someone (1) to whom one can confide on various issues, (2) who could provide instrumental help and (3) who could provide emotional support. A summative score, ranging from zero to 3 , was then calculated (higher scores indicating higher SS). The number of outpatient medical consultations and ED visits for any reason was obtained from the RAMQ medical registry, and the number of hospitalizations was obtained from the MEDÉCHO registry, for a period of 3 years prior to the interview. For this study, outpatient services delivered on the same day for the same person by two or more different medical practitioners were computed as different visits. An ED visit was identified as all claims for medical acts performed in this department on the same date, and hospitalization was defined as each hospital inpatient stay lasting more than $24 \mathrm{~h}$.

\section{Statistical analysis}

We used general descriptive statistics, and the results were expressed as absolute frequency and proportions or mean \pm standard deviation (SD). Bivariate analyses were performed using the chi-square test for categorical variables and Student's t-test for continuous variables. All statistical analyses were conducted using SPSS 25 with a statistical significance alpha level of 0.05 .

Differences in the observed prevalence of chronic conditions and of MM among data sources were assessed using Cochran's Q Test [47]. We calculated the relative percent (\%) difference of proportions obtained with single data sources (SR vs Adm) using the following formula: $[(A-B) / A]{ }^{*} 100 \%$, where (A) corresponds the higher proportion and (B) corresponds to the lower proportion obtained with an individual dataset (whether Adm or SR). The relative percent (\%) increase in prevalence that occurred when data sources were combined [48] was calculated using the following formula [(C-A) /A] " $100 \%$, where (C) corresponds to the proportion obtained with combined data sources and (A) corresponds the higher proportion obtained with an individual dataset (whether Adm or SR).

Agreement between the SR and Adm data sources on chronic conditions was assessed using kappa statistics ( $\mathrm{\kappa}$ ), positive (PA) and negative (NA) agreement, prevalence index (PI), bias index (BI) and prevalence-adjusted and bias-adjusted $\mathrm{\kappa}$ (PABAK). The PI measures the difference between the probability of "yes" and "no" categories for two observations or observers, while the BI describes how much the two observations or observers differ on the 
proportion of positive results. For any $2 \times 2$ table, these indexes can be estimated by $\mathrm{PI}=(\mathrm{a}-\mathrm{d}) / \mathrm{N}$ and $\mathrm{BI}=(\mathrm{b}-\mathrm{c}) / \mathrm{N}$ [49]. The range of possible values of $\mathrm{K}$ is from -1 to 1 , and their suggested interpretations are as follows: $\leq 0$ (no agreement); 0.01 to 0.20 (none to poor), 0.21 to 0.40 (fair), 0.41 to 0.60 (moderate), 0.61 to 0.80 (substantial), and 0.81 to 1.00 (almost perfect agreement) [50,51].

All data were anonymized. Missing data were estimated using an appropriate method for the imputation of categorical data. This method maximizes the consistency of the completed data as measured by Guttman's squared correlation ratio, as suggested by van Buuren and van Rijckevorsel [52].

\section{Ethics approval}

The research ethics board of the CIUSSS de l'Estrie-CHUS reviewed and approved the ESA-S project [\#2012-03]. Access to the health-administrative database was approved by the Commission d'accès à l'information du Québec (CAIQ).

\section{Results}

Comparisons between individuals with $(n=1625)$ and without $(n=140)$ available Adm data did not show statistically significant differences with respect to gender $(p=0.08)$, age group $(p=0.13)$, income $(p=0.06)$, marital status $(p=0.65)$, smoking habit $(p=0.71)$, perceived mental $(p=0.99)$ or physical $(p=0.40)$ health and MMSE score $(p=0.17)$. However, those for whom matched health-Adm data were not possible had a significantly lower level of education $(p=0.04)$, fewer selfreported chronic conditions $(p<0.01)$ and less social support $(p<0.01)$. The overall sample characteristics are shown in Table 1.

The prevalence of each of the 17 chronic conditions ranged from 3 to $57.4 \%, 1.2$ to $52.3 \%$ and 3.8 to $68.7 \%$ when using SR data only, Adm data only and either data sources, respectively (Fig. 1). Cochran's Q test indicated statistically significant differences among the three proportions (SR vs Adm vs either data sources) for all conditions. Our analysis showed relative percent differences ranging from 7.1 to $87.7 \%$, and when combining data sources, estimations of proportions increased from 4.4 to $50.8 \%$ for all conditions.

As Table 2 shows, concordance was highly variable, and the $\kappa$ coefficients ranged from 0.05 to 0.73 (poor to substantial agreement), whereas the PABAK varied from 0.16 to 0.93 . With the exception of hypertension, all chronic conditions had higher negative agreement than positive agreement.

The calculated prevalence of MM ranged from 61.9 to 95.9\%, and regardless of the operational definition used (MM2 or MM3), combined sources presented a higher prevalence, followed by SR and Adm data. Cochran's Q test indicated statistically significant differences among
Table 1 Sociodemographic and behavioural characteristics of the study population

\begin{tabular}{|c|c|c|}
\hline \multirow[t]{2}{*}{ Characteristics } & \multicolumn{2}{|l|}{$\begin{array}{l}\text { Total sample } \\
n=1625\end{array}$} \\
\hline & $\mathrm{n}$ & $\%$ \\
\hline \multicolumn{3}{|l|}{ Gender } \\
\hline M & 704 & 43.3 \\
\hline $\mathrm{F}$ & 921 & 56.7 \\
\hline \multicolumn{3}{|l|}{ Age groups } \\
\hline $65-69$ & 532 & 32.7 \\
\hline $70-74$ & 494 & 30.4 \\
\hline $75-79$ & 334 & 20.6 \\
\hline $80-84$ & 185 & 11.4 \\
\hline $85-89$ & 70 & 4.3 \\
\hline 90 et + & 10 & 0.6 \\
\hline \multicolumn{3}{|l|}{ Education (in years) } \\
\hline$<7$ & 409 & 25.2 \\
\hline $8-12$ & 714 & 43.9 \\
\hline$\geq 13$ & 502 & 30.9 \\
\hline \multicolumn{3}{|l|}{ Income } \\
\hline $0-25,000$ & 555 & 34.2 \\
\hline$\geq 25,000$ & 1070 & 65.8 \\
\hline \multicolumn{3}{|l|}{ Marital status } \\
\hline With partner & 1030 & 63.4 \\
\hline Without & 595 & 36.6 \\
\hline \multicolumn{3}{|l|}{ Perceived mental health } \\
\hline Excellent/very good & 1130 & 69.5 \\
\hline Good & 391 & 24.1 \\
\hline Fair/poor & 104 & 6.4 \\
\hline \multicolumn{3}{|l|}{ Perceived physical health } \\
\hline Excellent/very good & 896 & 55.1 \\
\hline Good & 469 & 28.9 \\
\hline Fair/poor & 260 & 16 \\
\hline \multicolumn{3}{|l|}{ Smoking } \\
\hline Never & 616 & 37.9 \\
\hline Former & 869 & 53.5 \\
\hline Current & 140 & 8.6 \\
\hline Social support (mean \pm SD) & $2.82(0.51)$ & \\
\hline Number of outpatient visits (mean \pm SD) & $25.66(22.66)$ & \\
\hline Number of ED visits (mean \pm SD) & $1.27(2.09)$ & \\
\hline Number of hospitalizations (mean \pm SD) & $0.45(1.00)$ & \\
\hline
\end{tabular}

Abbreviation: SD Standard deviation

the three proportions $(p<.001)$. The presence of MM (any definition) was associated with participant age and perceived health. In addition, health service utilization was consistently higher among participants with MM compared to those with no MM. The prevalence of self- 


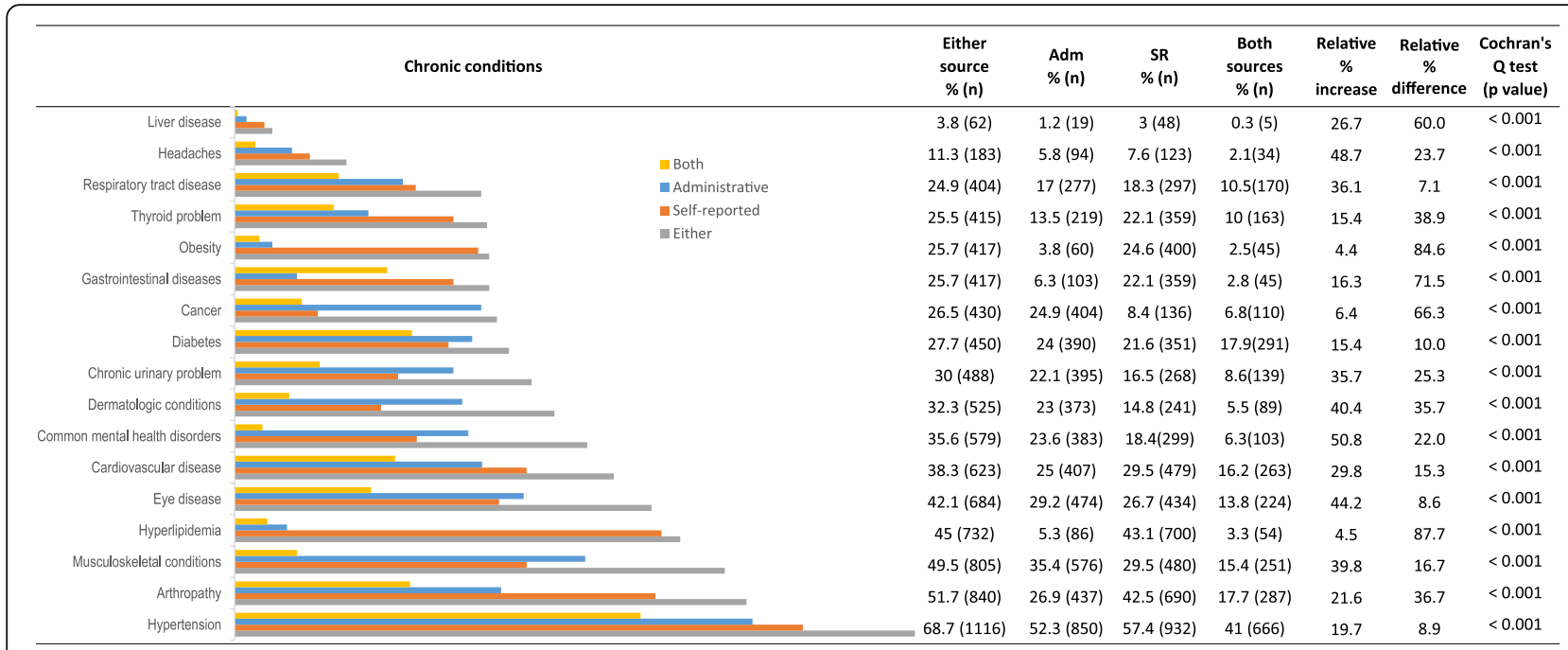

Fig. 1 Prevalence of chronic conditions by data sources and estimated relative percentage increase

reported MM (both cut-offs) was higher among females and participants without partners. These characteristics were also associated with the MM3_either definition, which is MM defined as $\geq 3$ chronic conditions from either data source. Higher income and education levels were associated with a lower prevalence of self-reported MM2 and MM3 (any definition). Smoking was associated with MM only when it was defined under the threshold of 3 conditions (SR only and Adm data only). Social support was significantly lower among certain multimorbid participants (i.e., MM3_SR and MM3_either) (Table 3).

\section{Discussion}

Regardless of the definition used, the prevalence of MM was high in this study. This finding is similar to results observed elsewhere $[3,5,53,54]$ that have included older adults in primary care settings and in which the assessment of MM included a list of at least 12 conditions [55]. Our findings add to the growing body of research highlighting MM not only as a major issue in primary care but also as a global health system issue for the care of older populations $[43,56]$.

To describe the health care needs and to propose appropriate management of care, it is necessary to take into account the heterogeneity of chronic diseases implicated in MM [4, 7]. This is particularly important in older people presenting with coexisting chronic physical and mental health conditions, who are considered highlevel complexity groups [7] with poorer health outcomes that require an individualized care approach [56, 57]. Our results suggest that integrating information from different data sources increases the identification of the presence of chronic conditions. Interestingly, this study showed that the proportions of common mental health conditions (SR vs Adm) had a relative percentage difference of $22 \%$. Moreover, when both data sources were combined, the estimation increased by $50.8 \%$. These findings align with earlier studies, based on older adults in the US and general population studies in Canada, that propose combining different data sources for improved case identification [58], particularly in neuropsychiatry $[48,59]$. Moreover, our study has been one of the first attempts to thoroughly examine the benefits of combining different data sources among a large sample of older adults consulting in primary care settings. This further highlights the important contribution of different data sources in the investigation of the prevalence of MM.

Furthermore, the estimated proportion of the sample with headaches, eye diseases, musculoskeletal and dermatologic conditions increased more than $40 \%$ when the data were combined. Based on a single source, 4 out of these 5 conditions had a higher prevalence according to the Adm database. The results also suggested the potential underestimation of chronic conditions when using one data source. We observed high relative percent differences (60 to $87.7 \%$ ) for obesity, cancer, hyperlipidemia, gastrointestinal and liver diseases, with 4 out of 5 conditions showing higher SR prevalence. These findings are in line with previous studies reporting inconsistencies in prevalence estimations due to the use of different data sources [23-25, 30, 31, 60]. Based on these results, if one were to use Adm data only, there would be an underestimate of the prevalence of obesity and hyperlipidemia. If one were to choose SR data only, there would be an underestimation of up to 3 times the prevalence of cancer as reported in Adm databases.

Moreover, even when the prevalence estimated with single datasets (not combined sources) was apparently similar (e.g., respiratory tract and eye diseases), the 
Table 2 Summary of agreement analysis for chronic conditions

\begin{tabular}{|c|c|c|c|c|c|c|c|}
\hline Chronic condition & $\begin{array}{l}\text { Kappa } \\
(95 \% \text { CI) }\end{array}$ & Interpretation & $\begin{array}{l}\text { Positive Agreement } \\
\text { (PA) }\end{array}$ & $\begin{array}{l}\text { Negative Agreement } \\
\text { (NA) }\end{array}$ & $\begin{array}{l}\text { Prevalence Index } \\
\text { (PI) }\end{array}$ & $\begin{array}{l}\text { Bias Index } \\
\text { (BI) }\end{array}$ & PABAK \\
\hline Liver disease & $0.13(0.02$ to 0.25$)$ & Poor & 0.15 & 0.98 & 0.96 & 0.02 & 0.93 \\
\hline Headaches & 0.27 (0.18 to 0.35$)$ & Fair & 0.31 & 0.95 & 0.87 & 0.02 & 0.82 \\
\hline Respiratory tract disease & 0.50 (0.45 to 0.56$)$ & Moderate & 0.59 & 0.91 & 0.65 & 0.01 & 0.71 \\
\hline Thyroid problem & $0.48(0.42$ to 0.53$)$ & Moderate & 0.57 & 0.91 & 0.64 & 0.09 & 0.69 \\
\hline Obesity & 0.14 (0.10 to 0.18$)$ & Poor & 0.20 & 0.86 & 0.71 & 0.21 & 0.53 \\
\hline Gastrointestinal diseases & 0.11 (0.06 to 0.15$)$ & Poor & 0.19 & 0.87 & 0.71 & 0.16 & 0.54 \\
\hline Cancer & 0.32 (0.27 to 0.38$)$ & Fair & 0.41 & 0.88 & 0.67 & 0.16 & 0.61 \\
\hline Diabetes & 0.73 (0.69 to 0.77 ) & Substantial & 0.79 & 0.94 & 0.54 & 0.02 & 0.81 \\
\hline Chronic urinary problem & $0.32(0.26$ to 0.37$)$ & Fair & 0.45 & 0.87 & 0.61 & 0.05 & 0.57 \\
\hline Dermatologic conditions & 0.14 (0.08 to 0.19$)$ & Poor & 0.29 & 0.84 & 0.62 & 0.08 & 0.47 \\
\hline $\begin{array}{l}\text { Common mental health } \\
\text { disorders }\end{array}$ & 0.12 (0.07 to 0.17 ) & Poor & 0.30 & 0.81 & 0.58 & 0.05 & 0.41 \\
\hline Cardiovascular disease & 0.44 (0.39 to 0.49 ) & Moderate & 0.59 & 0.85 & 0.45 & 0.04 & 0.56 \\
\hline Eye disease & $0.30(0.25$ to 0.35$)$ & Fair & 0.50 & 0.80 & 0.44 & 0.02 & 0.43 \\
\hline Hyperlipidemia & 0.05 (0.02 to 0.07$)$ & Poor & 0.14 & 0.72 & 0.51 & 0.38 & 0.16 \\
\hline Musculoskeletal conditions & 0.23 (0.18 to 0.28$)$ & Fair & 0.48 & 0.75 & 0.35 & 0.06 & 0.32 \\
\hline Arthropathy & 0.27 (0.23 to 0.32$)$ & Fair & 0.51 & 0.74 & 0.3 & 0.16 & 0.32 \\
\hline Hypertension & 0.45 (0.40 to 0.49 ) & Moderate & 0.75 & 0.69 & 0.1 & 0.06 & 0.45 \\
\hline
\end{tabular}

Abbreviation: $\mathrm{Cl}$ Confidence interval

calculated percentage increase obtained when combining both data sources suggests that our data sources identify different cases $[48,58]$.

As reported in previous studies including older populations, the agreement between data sources for the 17 chronic conditions was highly variable $[24,27,30,50]$. For some diagnoses, such as diabetes, agreement is good. This may be explained by the health policies aimed at chronic condition management programmes in primary care for diabetes including both health professional and patient participation in treatment management. For other diagnoses, such as cancer and mental health conditions, agreement is poorer. Although associated with a high burden on the health system, the episodic nature of common mental disorders and treatable cancers may have been underreported by patients if interviewed while in remission. Such variability in potential underreporting is an important aspect to be explored in future studies since it may play a central role in patient involvement in health care decision-making. In the particular case of obesity, the low agreement between data sources might have occurred because the cut-off for self-reported obesity (BMI $\geq 30)$ may not correspond to the one applied in clinical practice where clinicians would be more likely to code a diagnosis of obesity only when it aggravates another condition. Others have suggested that the low agreement may also be a case of less reliable Adm database coding where only the most severe cases of obesity would be recorded [61]. While this latter Canadian study was performed among hospitalized patients, our results support a similar pattern among older adults in the context of primary care. In terms of $\kappa$ values, our results are very similar to those presented by Fortin and colleagues (2017) [30]. However, according to the literature [22, 49, $50,60,62]$, this coefficient should not be reported or interpreted alone but rather jointly with other indicators. The $\mathrm{k}$ statistic takes into account not only the agreement occurring by chance but also the complex influence of the difference in the disagreement cells (BI) and the agreement cells (PI) in a $2 \times 2$ table [49]. Regardless of the chronic conditions assessed, our results showed that most $k$ coefficients were low (fair to poor) and that BI and PI varied widely and independently of each other. If we contrast pairs of conditions that showed the same $k$ values (e.g., dermatologic conditions and obesity; headaches and arthropathy; cancer and chronic urinary problems), we notice that the other indicators showed different values (Fig. 1; Table 2). Evaluating the set of reported indicators, not only the kappa, (Fig. 1; Table 2), leads to a better understanding of which conditions may be better identified when the different data sources are combined.

The prevalence of self-reported MM was higher than that of the cases identified through Adm data. Combining both databases allowed an increase of 10.6 and $22.4 \%$ in the estimation of MM2 and MM3 cases, leading to $95.9 \%$ of participants being identified as having two or more chronic conditions. Previous studies 
Table 3 Prevalence of MM according to different definitions and the participants' characteristics

\begin{tabular}{|c|c|c|c|c|c|c|}
\hline \multirow[t]{4}{*}{ Study sample $(n=1625)$} & \multicolumn{6}{|c|}{ Multimorbidity } \\
\hline & \multicolumn{3}{|c|}{ Cut-off 2+ } & \multicolumn{3}{|c|}{ Cut-off 3+ } \\
\hline & MM2_SR & MM2_Adm & MM2_either & MM3_SR & MM3_Adm & MM3_either \\
\hline & $86.7 \%(n=1409)$ & $81.8 \%(n=1330)$ & $95.9 \%(n=1558)$ & $72.9 \%(n=1184)$ & $61.9 \%(n=1006)$ & $89.2 \%(n=1449)$ \\
\hline Relative $\%$ difference & \multicolumn{3}{|c|}{$5.6 \%$} & \multicolumn{3}{|c|}{$15.1 \%$} \\
\hline Relative \% increase & \multicolumn{3}{|c|}{$10.6 \%$} & \multicolumn{3}{|c|}{$22.4 \%$} \\
\hline Cochran's Q test & \multicolumn{3}{|c|}{$220.95 p<.001$} & \multicolumn{3}{|c|}{$483.24 p<.001$} \\
\hline \multicolumn{7}{|l|}{ Gender } \\
\hline M & $83.2 \%$ & $81.8 \%$ & $95.0 \%$ & $69.2 \%$ & $61.4 \%$ & $87.2 \%$ \\
\hline \multirow[t]{2}{*}{$\mathrm{F}$} & $89.4 \%$ & $81.9 \%$ & $96.5 \%$ & $75.7 \%$ & $62.3 \%$ & $90.7 \%$ \\
\hline & $p<0.001$ & $p=0.980$ & $p=0.133$ & $p=0.003$ & $p=0.693$ & $p=0.027$ \\
\hline \multicolumn{7}{|l|}{ Age groups } \\
\hline $65-69$ & $80.6 \%$ & $77.8 \%$ & $93.0 \%$ & $66.9 \%$ & $54.1 \%$ & $83.1 \%$ \\
\hline $70-74$ & $89.3 \%$ & $81.4 \%$ & $95.7 \%$ & $74.3 \%$ & $62.3 \%$ & $91.1 \%$ \\
\hline $75-79$ & $89.5 \%$ & $85.6 \%$ & $98.5 \%$ & $77.2 \%$ & $67.1 \%$ & $92.2 \%$ \\
\hline $80-84$ & $89.2 \%$ & $86.5 \%$ & $98.4 \%$ & $75.7 \%$ & $69.7 \%$ & $95.1 \%$ \\
\hline $85-89$ & $92.9 \%$ & $85.7 \%$ & $98.6 \%$ & $77.1 \%$ & $71.4 \%$ & $91.4 \%$ \\
\hline \multirow[t]{2}{*}{90 and + } & $100.0 \%$ & $80.0 \%$ & $100.0 \%$ & $90.0 \%$ & $70.0 \%$ & $90.0 \%$ \\
\hline & $p=0.001$ & $p=0.033$ & $p=0.003$ & $p=0.006$ & $p<0.001$ & $p<0.001$ \\
\hline \multicolumn{7}{|l|}{ Education (in years) } \\
\hline$<7$ & $90,0 \%$ & $84.6 \%$ & $97.3 \%$ & $79,0 \%$ & $69.4 \%$ & $91.9 \%$ \\
\hline $8-12$ & $87.1 \%$ & $81.4 \%$ & $95.8 \%$ & $72.7 \%$ & $59.4 \%$ & $89.9 \%$ \\
\hline \multirow[t]{2}{*}{$\geq 13$} & $83.5 \%$ & $80.3 \%$ & $94.8 \%$ & $68.1 \%$ & $59.4 \%$ & $85.9 \%$ \\
\hline & $p=0.014$ & $p=0.221$ & $p=0.169$ & $p=0.001$ & $p=0.001$ & $p=0.009$ \\
\hline \multicolumn{7}{|l|}{ Income } \\
\hline $0-25,000$ & $90.8 \%$ & $83.2 \%$ & $96.9 \%$ & $80.4 \%$ & $65.4 \%$ & $93.2 \%$ \\
\hline \multirow[t]{2}{*}{$\geq 25,000$} & $84.6 \%$ & $81.1 \%$ & $95.3 \%$ & $69.0 \%$ & $60.1 \%$ & $87.1 \%$ \\
\hline & $p<0.001$ & $p=0.293$ & $p=0.122$ & $p<0.001$ & $p=0.037$ & $p<0.001$ \\
\hline \multicolumn{7}{|l|}{ Marital status } \\
\hline With partner & $84.6 \%$ & $82.2 \%$ & $95.2 \%$ & $70.8 \%$ & $61.4 \%$ & $87.7 \%$ \\
\hline \multirow[t]{2}{*}{ Without } & $90.4 \%$ & $81.2 \%$ & $97.0 \%$ & $76.5 \%$ & $62.9 \%$ & $91.8 \%$ \\
\hline & $p=0.001$ & $p=0.595$ & $p=0.091$ & $p=0.013$ & $p=0.549$ & $p=0.011$ \\
\hline \multicolumn{7}{|l|}{ Perceived mental health } \\
\hline Excellent/very good & $83.5 \%$ & $79.5 \%$ & $95,0 \%$ & $68.2 \%$ & $58.8 \%$ & $86.9 \%$ \\
\hline Good & $93.1 \%$ & $87,0 \%$ & $97.7 \%$ & $81.8 \%$ & $68.5 \%$ & $93.9 \%$ \\
\hline \multirow[t]{2}{*}{ Fair/poor } & $97.1 \%$ & $88.5 \%$ & $99,0 \%$ & $89.4 \%$ & $71.2 \%$ & $96.2 \%$ \\
\hline & $p<0.001$ & $p=0.001$ & $p=0.012$ & $p<0.001$ & $p<0.001$ & $p<0.001$ \\
\hline \multicolumn{7}{|l|}{ Perceived physical health } \\
\hline Excellent/very good & $79.2 \%$ & $75.8 \%$ & $93.5 \%$ & $60.8 \%$ & $52.3 \%$ & $83.8 \%$ \\
\hline Good & $94.8 \%$ & $87.2 \%$ & $98.5 \%$ & $83.8 \%$ & $68.7 \%$ & $94.2 \%$ \\
\hline Fair/poor & $97.7 \%$ & $93.1 \%$ & $99.2 \%$ & $94.6 \%$ & $82.7 \%$ & $98.5 \%$ \\
\hline & $p<0.001$ & $p<0.001$ & $p<0.001$ & $p<0.001$ & $p<0.001$ & $p<0.001$ \\
\hline Smoking & & & & & & \\
\hline Never & $85.9 \%$ & $79.5 \%$ & $95.3 \%$ & $69.2 \%$ & $58,0 \%$ & $88.5 \%$ \\
\hline Former & $86.5 \%$ & $83.8 \%$ & $96.2 \%$ & $75.0 \%$ & $65.4 \%$ & $89.4 \%$ \\
\hline
\end{tabular}


Table 3 Prevalence of MM according to different definitions and the participants' characteristics (Continued)

\begin{tabular}{|c|c|c|c|c|c|c|}
\hline \multirow[t]{4}{*}{ Study sample $(n=1625)$} & \multicolumn{6}{|c|}{ Multimorbidity } \\
\hline & \multicolumn{3}{|c|}{ Cut-off $2+$} & \multicolumn{3}{|c|}{ Cut-off 3+ } \\
\hline & MM2_SR & MM2_Adm & MM2_either & MM3_SR & MM3_Adm & MM3_either \\
\hline & $86.7 \%(n=1409)$ & $81.8 \%(n=1330)$ & $95.9 \%(n=1558)$ & $72.9 \%(n=1184)$ & $61.9 \%(n=1006)$ & $89.2 \%(n=1449)$ \\
\hline \multirow[t]{2}{*}{ Current } & $91.4 \%$ & $80.0 \%$ & $96.4 \%$ & $75.7 \%$ & $57.9 \%$ & $90.7 \%$ \\
\hline & $p=0.212$ & $p=0.096$ & $p=0.646$ & $p=0.031$ & $p=0.009$ & $p=0.702$ \\
\hline \multirow[t]{2}{*}{ Social support (mean \pm SD) } & $2.82(0.51)^{\mathrm{a}}$ & $2.83(0.48)^{a}$ & $2.82(0.51)^{a}$ & $2.80(0.53)^{\mathrm{a}}$ & $2.82(0.51)^{\mathrm{a}}$ & $2.82(0.52)^{a}$ \\
\hline & $p=0.221$ & $p=0.259$ & $p=0.959$ & $p=0.004$ & $p=0.483$ & $p=0.035$ \\
\hline \multirow[t]{2}{*}{ Number of outpatient visits (mean \pm SD) } & $27.04(23.48)^{a}$ & $28.58(23.63)^{a}$ & $26.28(22.83)^{a}$ & $28.84(24.61)^{a}$ & $32.21(25.42)^{a}$ & $27.31(23.24)^{a}$ \\
\hline & $p<0.001$ & $p<0.001$ & $p<0.001$ & $p<0.001$ & $p<0.001$ & $p<0.001$ \\
\hline \multirow[t]{2}{*}{ Number of ED visits (mean \pm SD) } & $1.36(2.18)^{a}$ & $1.44(2.21)^{\mathrm{a}}$ & $1.30(2.11)^{\mathrm{a}}$ & $1.47(2.28)^{\mathrm{a}}$ & $1.72(2.41)^{\mathrm{a}}$ & $1.37(2.17)^{\mathrm{a}}$ \\
\hline & $p<0.001$ & $p<0.001$ & $p<0.001$ & $p<0.001$ & $p<0.001$ & $p<0.001$ \\
\hline \multirow[t]{2}{*}{ Number of hospitalizations (mean \pm SD) } & $0.49(1.04)^{\mathrm{a}}$ & $0.52(1.06)^{\mathrm{a}}$ & $0.46(1.01)^{\mathrm{a}}$ & $0.53(1.10)^{\mathrm{a}}$ & $0.65(1.18)^{\mathrm{a}}$ & $0.48(1.03)^{\mathrm{a}}$ \\
\hline & $p<0.001$ & $p<0.001$ & $p=0.003$ & $p<0.001$ & $p<0.001$ & $p<0.001$ \\
\hline
\end{tabular}

Abbreviations: $E D$ Emergency department, $M M$ Multimorbidity, $S D$ Standard deviation

${ }^{\mathrm{a}}$ Compared to those without MM (any definition)

focusing on older adults and using patient chart or electronic health records (EHR) in a primary care setting also reported a MM prevalence higher than 90\% [17, 63]. Many public health systems in Canada are investing in EHR [64]. Future studies should focus on comparing EHR to datasets derived from combined data sources such as SR and Adm [23, 65]. Rendering this possible requires policies that facilitate data access.

This study also showed an association between a number of sociodemographic and behavioural factors and the presence of MM defined according to different data sources and cut-offs. For example, gender was not associated with MM measured with Adm data but was associated with self-reported MM (any cut-off). This finding is in line with the idea presented in previous studies [15, $30,31]$ that different population subgroups are captured when different data sources and operational criteria are used to identify MM cases. This may highlight the influence of certain biopsychosocial factors reflected in SR data but less so in Adm data based on physician diagnoses.

\section{Limitations}

The limited number of chronic conditions included in this study $(n=17)$ can be seen as a first limitation. According to the literature, the greater number of comorbidities, the greater the possibility that MM will be identified [16, 17]. However, there is still no standardized solution as to the ideal size of the list of conditions [10, 15]. Nevertheless, we included 10 of the 11 diagnoses suggested by Diederichs and colleagues [66] as the most frequent diagnoses for people aged 65 years and older and $90 \%$ of those recently suggested by Fortin and colleagues [67]. Moreover, the content validity of our chronic condition list, which was influenced by lists proposed by experts in the MM field, may be considered a strength. Second, the use of other self-reported or claimbased information, such as pharmacological or nonpharmacological treatments, laboratory tests and medical procedures, would increase the reliability of diagnosis, but this was not feasible in the current study $[5,43]$. The test results received by patients may lead to more accurate self-reports, whereas physicians may add a diagnosis to the visit in view of further testing to confirm or rule out a disorder.

Third, prevalence estimates of certain conditions according to the Adm database might have been overestimated because some codes may indicate a tentative diagnosis. The use of selected algorithms (e.g., at least two outpatient diagnostics within a year), which were not used in this study, might have reduced this potential bias [30, 60, 68]. A previous Canadian study [26], however, showed no benefit in using restrictive criteria for defining a case. Since information about diagnostic codes is not mandatory in the RAMQ medical services claims database, this kind of restriction may lead to an underestimation of cases. Nevertheless, the use of MEDÉCHO data on hospitalizations may lead to improved sensitivity of measures. Further studies are needed to explore and compare these aspects.

The reasons for the differences in terms of agreement are not straightforward and, based on the information available in this study, can only be hypothesized. The literature proposes several factors influencing agreement. For example, we used a 3 year look-back window, and the use of additional years may have increased the agreement between the two data sources [26, 30, 31, 69]. Furthermore, a relatively low prevalence of certain diseases 
(e.g., liver diseases and headaches) might affect the kappa coefficients, thus reinforcing the relevance of presenting other agreement measures [60]. Additionally, the results reported based on Adm databases depend on coding accuracy, while those based on SR data depend on respondents' health literacy and memory [22, 25, 68]. Stigmatization and social desirability can also influence the reporting of certain conditions (e.g., cancer; mental health disorders) $[27,59,70]$. Not using a timeframe as to the presence of a self-reported health condition in our survey question may also have contributed to the low agreement between data sources, especially in the case of episodic chronic conditions such as urinary and dermatologic conditions $[60,69]$.

The association between sociodemographic and behavioural variables was not consistent for all MM definitions, and only bivariate models were tested. Further research using multivariate models is needed to examine the simultaneous relationship of multiple independent variables and $\mathrm{MM}$ according to different definitions. Additionally, future studies using combined data sources should consider an examination of outcomes such as quality of life, functional autonomy and associated health care costs.

Finally, the transferability of results is limited to older adult primary care service users within the context of a universal public health care system. Moreover, more global validation studies concerning Quebec's health-Adm data are still needed since most of the previous studies were limited to a restricted set of conditions or populations $[69,71-74]$.

\section{Conclusion}

This is the first study to address, in primary care older adults, the concordance between SR and Adm data in the context of a public health system where residents are covered for all hospitalizations and outpatient consultations with physicians. This study also goes beyond the present literature by simultaneously investigating MM (according to two operational definitions) and chronic condition prevalence. Our findings suggest that no single data source is more valid than another, and we highlight the usefulness of combining two data sources that may, in fact, reflect different patient (SR) and health system (Adm) perspectives. Furthermore, the populations identified by each data source may present different clinical and need profiles. Given the increasing prevalence of MM due to the ageing population, policy and decision makers need to consider both Adm and SR data when estimating population health needs to be able to adequately allocate health and human resources to ensure quality of care and to improve the efficiency of the healthcare system.

\section{Additional file}

Additional file 1: Table S1. List of 17 chronic conditions categories and corresponding International Classification of Disease, $9^{\text {th }}$ and $10^{\text {th }}$ Revisions (ICD-9/ICD-10). This table includes all ICD-9 and ICD-10 codes that had been used to extract information from administrative databases. (DOCX $20 \mathrm{~kb}$ )

\section{Abbreviations}

Adm: Administrative; BI: Bias index; BMI: Body mass index; CAIQ : Commission d'accès à l'information du Québec; Cl: Confidence interval; DSM- 5: Diagnostic and Statistical Manual of Mental Disorders, 5th edition; ED: Emergency department; EHR: Electronic health records; Either: Combined sources; ESA-S: Enquête sur la santé des aînés-Services; ESA-S Q: The ESA-S computer-administered questionnaire; GAD: Generalized anxiety disorder; ICD-10: International Statistical Classification of Diseases and Related Health Problems, 10th revision; ICD-9: International Statistical Classification of Diseases and Related Health Problems, 9th revision; IRCMo: International Research Community on Multimorbidity; MED-ÉCHO: Maintenance et exploitation des données pour l'étude de la clientèle hospitalière; MM: Multimorbidity; MM2: Variable multimorbidity defined as the presence of $\geq 2$ chronic conditions; MM2_Adm: Variable multimorbidity defined as the presence of $\geq 2$ chronic conditions_administrative data only;

MM2_Either: Variable multimorbidity defined as the presence of $\geq 2$ chronic conditions_combined data sources; MM2_SR: Variable multimorbidity defined as the presence of $\geq 2$ chronic conditions_self-reported data only; MM3: Variable multimorbidity defined as the presence of $\geq 3$ chronic conditions; MM3_Adm: Variable multimorbidity defined as the presence of $\geq 3$ chronic conditions_administrative data only; MM3_Either: Variable multimorbidity defined as the presence of $\geq 3$ chronic conditions_combined data sources; MM3_SR: Variable multimorbidity defined as the presence of $\geq 3$ chronic conditions_self-reported data only; MMSE: Mini-Mental State Examination; NA: Negative agreement; NAM: Numéro d'assurance maladie; PA: Positive agreement; PABAK: Prevalence-adjusted and bias-adjusted K; PI: Prevalence index; RAMQ : Régie de I'Assurance Maladie Québec; SD: Standard deviation; SR: Survey/self-reported; k: Kappa coefficients

\section{Acknowledgements}

The authors express their gratitude to Dr. Fortin for his great contribution in the selection of the diagnostic codes. We gratefully acknowledge the contribution of the late Prof. Michel Préville to the ESA-S study.

\section{Authors' contributions}

SGG conceived this study and drafted the manuscript. DB created/prepared the dataset for analyses. All of the authors were involved in designing the study and contributed substantially to the data analysis and interpretation. All authors also participated in revising the manuscript, providing final approval of the version to be published, and agree to be accountable for all aspects of the work.

\section{Funding}

This ESA-S study was supported in part by a Quebec Health Research Fund (FRQS) operating grant (ref: 16000). The corresponding author holds a CIHR Doctoral Research Award the Frederick Banting and Charles Best Canada Graduate Scholarships Doctoral Awards (CGSD) (ref: GSD 146258). During the ESA-S study, Dr. Vasiliadis was supported by a Junior 2 Research Salary award of the FRQS and currently holds a FRQS Senior Research salary award. The funders had no role in the study design, data collection, analysis and interpretation, draft and revision of the paper nor in the decision to submit for publication.

\section{Availability of data and materials}

Requests for access to full anonymized dataset should be addressed to the corresponding author. Participants were not requested to give informed consent for data sharing with other researchers outside the team.

\section{Ethics approval and consent to participate}

All procedures performed in studies involving human participants were in accordance with the ethical standards of the institutional committee. The ESA-S project was reviewed and approved by the research ethics board of 
the CIUSSS de I'Estrie-CHUS (Projet \#2012-03). Access to the healthadministrative database was approved by the Commission d'accès à l'information du Québec (CAIQ) (\#110368). All participants signed informed consent forms allowing for the linking of datasets and access of data to research team.

\section{Consent for publication}

"Not applicable".

\section{Competing interests}

The authors declare that they have no competing interests.

\section{Author details}

${ }^{1}$ Centre de recherche Charles-Le Moyne - Saguenay-Lac-Saint-Jean sur les innovations en santé (CR-CSIS), Longueuil, QC, Canada. ${ }^{2}$ Université de Sherbrooke, Campus Longueuil, 150 Place Charles-Le Moyne, Longueuil, QC J4K 0A8, Canada. ${ }^{3}$ Department of Community Health Sciences, Faculty of Medicine and Health Sciences, Université de Sherbrooke, Longueuil, QC, Canada.

Received: 13 December 2018 Accepted: 29 May 2019

Published online: 14 June 2019

\section{References}

1. van den Akker M, Buntinx F, Knottnerus JA. Comorbidity or multimorbidity: what's in a name? A review of literature. Eur J Gen Pract. 1996;2:65-70.

2. Violan C, Foguet-Boreu Q, Flores-Mateo G, Salisbury C, Blom J, Freitag M, et al. Prevalence, determinants and patterns of multimorbidity in primary care: a systematic review of observational studies. PLoS One. 2014;9:e102149.

3. Cassell A, Edwards D, Harshfield A, Rhodes K, Brimicombe J, Payne R, et al. The epidemiology of multimorbidity in primary care: a retrospective cohort study. Br J Gen Pract. 2018;68:e245-51.

4. Wilson M, Lavis J, Gauvin F-P. Designing integrated approaches to support people with multimorbidity: key messages from systematic reviews, health system leaders and citizens. Healthc Policy Polit Santé. 2016;12:91-104.

5. Barnett K, Mercer SW, Norbury M, Watt G, Wyke S, Guthrie B. Epidemiology of multimorbidity and implications for health care, research, and medical education: a cross-sectional study. Lancet. 2012;380:37-43.

6. Briggs AM, Araujo de Carvalho I. Actions required to implement integrated care for older people in the community using the World Health Organization's ICOPE approach: a global Delphi consensus study. PLoS One. 2018;13:e0205533.

7. National Guideline Centre (UK). Multimorbidity: assessment, prioritisation and management of care for people with commonly occurring multimorbidity. London: Commissioned by the National Institute for Health and Care Excellence; 2016.

8. Prince MJ, Wu F, Guo Y, Gutierrez Robledo LM, O'Donnell M, Sullivan R, et al. The burden of disease in older people and implications for health policy and practice. Lancet. 2015;385:549-62.

9. Poitras $M-E$, Maltais $M-E$, Bestard-Denommé $L$, Stewart $M$, Fortin M. What are the effective elements in patient-centered and multimorbidity care? A scoping review. BMC Health Serv Res. 2018;18. https://doi.org/10.1186/ s12913-018-3213-8.

10. Xu X, Mishra GD, Jones M. Evidence on multimorbidity from definition to intervention: an overview of systematic reviews. Ageing Res Rev. 2017;37: 53-68.

11. Johnston MC, Crilly M, Black C, Prescott GJ, Mercer SW. Defining and measuring multimorbidity: a systematic review of systematic reviews. Eur J Pub Health. 2018. https://doi.org/10.1093/eurpub/cky098.

12. Marengoni A, Angleman S, Melis R, Mangialasche F, Karp A, Garmen A, et al. Aging with multimorbidity: a systematic review of the literature. Ageing Res Rev. 2011;10:430-9.

13. Lefèvre T, d'Ivernois J-F, De Andrade V, Crozet C, Lombrail P, Gagnayre R. What do we mean by multimorbidity? An analysis of the literature on multimorbidity measures, associated factors, and impact on health services organization. Rev Epidemiol Sante Publique. 2014;62:305-14.

14. Roberts KC, Rao DP, Bennett TL, Loukine L, Jayaraman GC. Prevalence and patterns of chronic disease multimorbidity and associated determinants in Canada. Health Promot Chronic Dis Prev Can. 2015;35:87-94.

15. Ramond-Roquin A, Haggerty J, Lambert M, Almirall J, Fortin M. Different multimorbidity measures result in varying estimated levels of physical quality of life in individuals with multimorbidity: a cross-sectional study in the general population. Biomed Res Int. 2016;2016:1-9.

16. Harrison C, Britt H, Miller G, Henderson J. Examining different measures of multimorbidity, using a large prospective cross-sectional study in Australian general practice. BMJ Open. 2014;4:e004694.

17. Fortin M, Hudon C, Haggerty J, van den Akker M, Almirall J. Prevalence estimates of multimorbidity: a comparative study of two sources. BMC Health Serv Res. 2010;10. https://doi.org/10.1186/1472-6963-10-111.

18. Mokraoui N-M, Haggerty J, Almirall J, Fortin M. Prevalence of self-reported multimorbidity in the general population and in primary care practices: a cross-sectional study. BMC Res Notes. 2016;9. https://doi.org/10.1186/ s13104-016-2121-4.

19. van den Bussche H, Schäfer I, Wiese B, Dahlhaus A, Fuchs A, Gensichen J, et al. A comparative study demonstrated that prevalence figures on multimorbidity require cautious interpretation when drawn from a single database. J Clin Epidemiol. 2013;66:209-17.

20. Pache B, Vollenweider P, Waeber G, Marques-Vidal P. Prevalence of measured and reported multimorbidity in a representative sample of the Swiss population. BMC Public Health. 2015;15. https://doi.org/10.1186/ s12889-015-1515-x.

21. Violán C, Foguet-Boreu Q, Hermosilla-Pérez E, Valderas JM, Bolíbar B, Fàbregas-Escurriola $M$, et al. Comparison of the information provided by electronic health records data and a population health survey to estimate prevalence of selected health conditions and multimorbidity. BMC Public Health. 2013;13:251.

22. De-loyde KJ, Harrison JD, Durcinoska I, Shepherd HL, Solomon MJ, Young JM. Which information source is best? Concordance between patient report, clinician report and medical records of patient co-morbidity and adjuvant therapy health information: which information source is best? J Eval Clin Pract. 2015;21:339-46.

23. St. Clair P, Gaudette É, Zhao H, Tysinger B, Seyedin R, Goldman DP. Using self-reports or claims to assess disease prevalence: it's complicated. Med Care. 2017;55:782-8.

24. Jiang L, Zhang B, Smith ML, Lorden AL, Radcliff TA, Lorig K, et al. Concordance between self-reports and medicare claims among participants in a National Study of chronic disease self-management program. Front Public Health. 2015;3. https://doi.org/10.3389/fpubh.2015.00222.

25. Muggah E, Graves E, Bennett C, Manuel DG. Ascertainment of chronic diseases using population health data: a comparison of health administrative data and patient self-report. BMC Public Health. 2013;13:16.

26. Robinson JR, Young TK, Roos LL, Gelskey DE. Estimating the burden of disease: comparing administrative data and self-reports. Med Care. 1997;35: 932-47.

27. Hansen H, Schäfer I, Schön G, Riedel-Heller S, Gensichen J, Weyerer S, et al. Agreement between self-reported and general practitioner-reported chronic conditions among multimorbid patients in primary care - results of the MultiCare cohort study. BMC Fam Pract. 2014;15. https://doi.org/10.1186/ 1471-2296-15-39.

28. Olomu AB, Corser WD, Stommel M, Xie Y, Holmes-Rovner M. Do self-report and medical record comorbidity data predict longitudinal functional capacity and quality of life health outcomes similarly? BMC Health Serv Res. 2012;12. https://doi.org/10.1186/1472-6963-12-398.

29. Bayliss EA, Ellis JL, Shoup JA, Zeng C, McQuillan DB, Steiner JF. Association of patient-centered outcomes with patient-reported and ICD-9-based morbidity measures. Ann Fam Med. 2012;10:126-33.

30. Fortin M, Haggerty J, Sanche S, Almirall J. Self-reported versus health administrative data: implications for assessing chronic illness burden in populations. A cross-sectional study. CMAJ Open. 2017;5:E729-33.

31. Lujic S, Simpson JM, Zwar N, Hosseinzadeh H, Jorm L. Multimorbidity in Australia: comparing estimates derived using administrative data sources and survey data. PLoS One. 2017;12:e0183817.

32. National Bureau of Economic Research (NBER). Expanding the National Health Expenditure Accounts (NHEA) technical documentation. 2009. http:// www.nber.org/aging/nha/Techandresults_spending/Techdoc_NBER_NHA_ Chapters1_9.pdf. Accessed 23 Nov 2018.

33. Zellweger U, Bopp M, Holzer BM, Djalali S, Kaplan V. Prevalence of chronic medical conditions in Switzerland: exploring estimates validity by comparing complementary data sources. BMC Public Health. 2014;14:1157.

34. Meyer BD, Mittag N. Using linked survey and administrative data to better measure income: implications for poverty, program effectiveness and holes in the safety net: W.E. Upjohn Institute; 2015. https://doi.org/10.17848/wp15-242. 
35. Vasiliadis H-M, Chudzinski V, Gontijo-Guerra S, Préville M. Screening instruments for a population of older adults: the 10-item Kessler psychological distress scale (K10) and the 7-item generalized anxiety disorder scale (GAD-7). Psychiatry Res. 2015;228:89-94.

36. Folstein MF, Folstein SE, McHugh PR. Mini-mental state. J Psychiatr Res. 1975;12:189-98.

37. Crum RM, Anthony JC, Basset SS, Folstein MF. Population-based norms for the mini-mental state examination by age and educational level. JAMA. 1993;269:2386-91

38. American Psychiatric Association APA. Diagnostic and statistical manual of mental disorders. 5th ed. Washington, DC: American Psychiatric Publishing; 2013.

39. Rodríguez MR, Nuevo R, Chatterij S, Ayuso-Mateos JL. Definitions and factors associated with subthreshold depressive conditions: a systematic review. BMC Psychiatry. 2012;12. https://doi.org/10.1186/1471-244X-12-181.

40. Sadek N, Bona J. Subsyndromal symptomatic depression: a new concept. Depress Anxiety. 2000;12:30-9.

41. Shields M, Carroll MD, Ogden CL. Adult obesity prevalence in Canada and the United States. NCHS Data Brief. 2011;56:1-8.

42. Nicholson K, Terry AL, Fortin M, Williamson T, Bauer M, Thind A. Examining the prevalence and patterns of multimorbidity in Canadian primary healthcare: a methodologic protocol using a national electronic medical record database. J Comorbidity. 2015:5:150-61.

43. Calderón-Larrañaga A, Vetrano DL, Onder G, Gimeno-Feliu LA, CoscollarSantaliestra C, Carfí A, et al. Assessing and measuring chronic multimorbidity in the older population: a proposal for its operationalization. J Gerontol A Biol Sci Med Sci. 2016. https://doi.org/10.1093/gerona/glw233.

44. Lesage A, Émond V. Surveillance des troubles mentaux au Québec : prévalence, mortalité et profil d'utilisation des services. Québec: Institut national de santé publique du Québec; 2012. https://www.inspq.qc.ca/pdf/publications/1578_ SunTroublesMentauxQc_PrevalMortaProfilUtiliServices.pdf

45. Fils JM, Penick EC, Nickel EJ, Othmer E, DeSouza C, Gabrielli WF, et al. Minor versus major depression: a comparative clinical study. Prim Care Companion J Clin Psychiatry. 2010. https://doi.org/10.4088/PCC.08m00752blu.

46. Holzer BM, Siebenhuener K, Bopp M, Minder CE. Overcoming cut-off restrictions in multimorbidity prevalence estimates. BMC Public Health. 2014;14:780

47. Cochran WG. The comparison of percentages in matched samples. Biometrika. 1950;37(3/4):256-66.

48. Schüssler-Fiorenza Rose SM, Xie D, Streim JE, Pan Q, Kwong PL, Stineman MG. Identifying neuropsychiatric disorders in the medicare current beneficiary survey: the benefits of combining health survey and claims data. BMC Health Serv Res. 2016;16. https://doi.org/10.1186/s12913-016-1774-y.

49. Byrt T, Bishop J, Carlin JB. Bias, prevalence and kappa. J Clin Epidemiol. 1993; 46:423-9.

50. Wolinsky FD, Jones MP, Ullrich F, Lou Y, Wehby GL. The concordance of survey reports and medicare claims in a nationally representative longitudinal cohort of older adults. Med Care. 2014;52:462-8.

51. Sim J, Wright CC. The kappa statistic in reliability studies: use, interpretation, and sample size requirements. Phys Ther. 2005;85:257-68

52. van Buuren S, van Rijckevorsel JLA. Imputation of missing categorical data by maximizing internal consistency. Psychometrika. 1992;57:567-80.

53. Stewart M, Fortin M, Britt HC, Harrison CM, Maddocks HL. Comparisons of multi-morbidity in family practice--issues and biases. Fam Pract. 2013;30: 473-80

54. Haggerty J, Fortin M, Breton M. Snapshot of the primary care waiting room: informing practice redesign to align with the patient's medical home model. Can Fam Physician. 2018;64:e407-13.

55. Fortin M, Stewart M, Poitras M-E, Almirall J, Maddocks H. A systematic review of prevalence studies on multimorbidity: toward a more uniform methodology. Ann Fam Med. 2012;10:142-51.

56. The Lancet. Making more of multimorbidity: an emerging priority. Lancet. 2018;391:1637

57. Yarnall AJ, Sayer AA, Clegg A, Rockwood K, Parker S, Hindle JV. New horizons in multimorbidity in older adults. Age Ageing. 2017:46:882-8.

58. Bayliss EA, Ellis JL, Steiner JF. Seniors' self-reported multimorbidity captured biopsychosocial factors not incorporated into two other data-based morbidity measures. J Clin Epidemiol. 2009;62:550-557.e1.

59. Drapeau A, Boyer R, Diallo FB. Discrepancies between survey and administrative data on the use of mental health services in the general population: findings from a study conducted in Quebec. BMC Public Health 2011;11:837.

60. Wu C-S, Lai M-S, Gau SS-F, Wang S-C, Tsai H-J. Concordance between patient self-reports and claims data on clinical diagnoses, medication use, and health system utilization in Taiwan. PLoS One. 2014;9:e112257.

61. Martin B-J, Chen G, Graham M, Quan H. Coding of obesity in administrative hospital discharge abstract data: accuracy and impact for future research studies. BMC Health Serv Res. 2014;14:70.

62. Chen G, Faris P, Hemmelgarn B, Walker RL, Quan H. Measuring agreement of administrative data with chart data using prevalence unadjusted and adjusted kappa. BMC Med Res Methodol. 2009;9. https://doi.org/10.1186/ 1471-2288-9-5.

63. Foguet-Boreu Q, Violán C, Rodriguez-Blanco T, Roso-Llorach A, Pons-Vigués M, Pujol-Ribera $E$, et al. Multimorbidity patterns in elderly primary health care patients in a South Mediterranean European region: a cluster analysis. PLoS One. 2015;10:e0141155.

64. Chang F, Gupta N. Progress in electronic medical record adoption in Canada. Can Fam Physician. 2015;61:1076.

65. Casey JA, Schwartz BS, Stewart WF, Adler NE. Using electronic health records for population health research: a review of methods and applications. Annu Rev Public Health. 2016;37:61-81.

66. Diederichs $\mathrm{C}$, Berger K, Bartels DB. The measurement of multiple chronic diseases--a systematic review on existing multimorbidity indices. J Gerontol A Biol Sci Med Sci. 2011:66A:301-11.

67. Fortin M, Almirall J, Nicholson K. Development of a research tool to document self-reported chronic conditions in primary care. J Comorbidity. 2017;7:117-23.

68. Feely A, Lix LM, Reimer K. Estimating multimorbidity prevalence with the Canadian chronic disease surveillance system. Health Promot Chronic Dis Prev Can. 2017;37:215-22.

69. Wilchesky M, Tamblyn RM, Huang A. Validation of diagnostic codes within medical services claims. J Clin Epidemiol. 2004;57:131-41.

70. Tisnado DM, Adams JL, Liu H, Damberg CL, Chen W-P, Hu FA, et al. What is the concordance between the medical record and patient self-report as data sources for ambulatory care? Med Care. 2006:44(2):132-40.

71. Daigle J-M, Saint Laurent D. L'utilisation des données médicoadministratives et leur jumelage: l'approche privilégiée en surveillance des maladies chroniques au Québec. Bull Epidémilogique Hebd. 2006;40-41: 300-2.

72. Firoozi F, Lemière C, Beauchesne M-F, Forget A, Blais L. Development and validation of database indexes of asthma severity and control. Thorax. 2007; 62:581.

73. Landry JS, Croitoru M, Menzies D. Validation des codes de diagnostic de la CIM-9 pour la dysplasie bronchopulmonaire dans les bases de donne'es de la Régie de l'assurance-maladie du Québec. Mal Chron Blessures Au Can. 2012;33:54-60.

74. Lacasse A, Ware MA, Dorais M, Lanctôt H, Choinière M. Is the Quebec provincial administrative database a valid source for research on chronic non-cancer pain? Pharmacoepidemiol Drug Saf. 2015;24:980-90.

\section{Publisher's Note}

Springer Nature remains neutral with regard to jurisdictional claims in published maps and institutional affiliations. 